\title{
Wire Ropes in Crane Applications - Current State of the Standardization Work of ISO/WD 16625
}

\author{
Judith Reinl ${ }^{1 *}$, Markus Golder ${ }^{2}$ \\ 1 Convenor ISO/TC 96 SC3 WG3, Germany \\ 2 Professorship of Conveying Engineering and Materials Handling, Chemnitz University of Technology, Germany \\ * Correspondence: judithreinl@aol.com
}

Received 28 October 2020; Accepted 28 October 2020; Available online 7 December 2020

(C) 2020 by J. Reinl and M. Golder. This is an open access article distributed under the Creative Commons Attribution License (CC-BY 4.O), which permits unrestricted use, distribution, and reproduction in any medium, provided the original work is properly cited.

\begin{abstract}
Nowadays, modern standards apply the proof of competence method to prove that a design force does not exceed a certain limit to ensure a certain safety level. Furthermore, standards elaborated during the last years apply a cycle-based approach instead of a time-based approach. The shortcomings of the standard ISO 16625:2013 need to be addressed in a revision. Therefore, a working group WG3 of ISO/TC 96 SC3 has been established in 2015 to prepare a new working draft ISO/WD 16625. Objectives are to adopt a cycle-based approach and to incorporate proofs of competence for static strength and fatigue strength for running ropes and stationary ropes, based on scientific inputs. The research work about steel wire ropes by the University of Stuttgart and the Technical University of Dresden developed the method Stuttgart and the method Leipzig, both representing regression models to determine the attainable number of bending cycles of a wire rope. The present paper briefly explains the method Leipzig and the method Stuttgart in chapter 3. In chapter 4, the partly implementation of findings from the method Stuttgart to the standard EN 13001-3-2:2014 is discussed and shortcomings are identified. Those shortcomings have also been addressed by the new developed concept of ISO/WD 16625 that is outlined in chapter 5. Finally, chapter 6 provides an overview on the revised ISO/WD 16625 to conclude the current state of the standardization work.
\end{abstract}

KEYWORDS ISO 16625, wire rope, fatigue, bending, proof of competence, running rope, stationary rope

\section{Introduction}

The international standard ISO 16625 Cranes and hoists - Selection of wire ropes, drums and sheaves, valid in its first edition from 2013, specifies a minimum design factor $Z_{p}$ taking mainly into account the classification of mechanism, the rope type and the application. [1] In ISO 16625:2013, the group classification of mechanism is in accordance with ISO 4301-1:1986 and thus follows a time-based approach. [2] Considering the maximum rope tension $S$ and selecting a specified value of the minimum design factor $Z_{p}$, the minimum breaking force of the rope $F_{\min }$ is determined by a simple calculation [1]:

$$
F_{\text {min }} \geq S \times Z_{p}
$$


Nowadays, modern standards apply the proof of competence method to prove that a design force does not exceed a certain limit to ensure a certain safety level. The (limit) design force itself is not determined by specified values, it is rather calculated considering influencing factors. Furthermore, standards elaborated during the last few years applying a cycle-based approach instead of a time-based approach. [3]

The shortcomings of ISO 16625:2013 are obvious: a time-based approach, i.e. the total duration of use, of the classification of mechanism forms the foundation to select a minimum design factor $Z_{p}$ although components of a mechanism are worn by stress cycles. Furthermore, the first edition of ISO 16625 misses a link to scientific-based results on impacts from bending stress or tensile loads during operation. A revision of ISO 16625:2013 is necessary.

\section{Objectives of a Revision of ISO 16625}

In 2015, subcommittee SC3 of ISO/TC 96 established a working group WG3 to revise ISO 16625:2013 to address the above stated shortcomings. A new revision of ISO 16625 shall adopt a cycle-based approach, e.g. as outlined in ISO 4301-1:2016 or EN 13001-3-2:2014 [2, 4], and should incorporate modern methods to provide a proof that the limits of fatigue strength and static strength of a wire rope - in relation to the drum and sheave geometry or load bearing structure - are met. Furthermore, a revision of ISO 16625 shall be enhanced to address the requirements of wire ropes in multi-layer spooling. Also, the difference of running ropes that are under bending stress permanently in contact with drums and sheaves and stationary ropes that are primarily under tensile load having no contact with drums or sheaves must be considered.

Another objective is to implement modern, well-known methods and to incorporate scientific proven input from wire rope tests like bending tests or tension-tension tests as a foundation of a revision of ISO 16625. Thus, a broad expertise from different areas is required and representatives from universities, research institutes, wire rope manufacturers and crane and hoist manufactures collaborate in the standardization activities of ISO/TC 96 SC3 WG3.

\section{Scientific Studies and Best Practice}

\subsection{Overview}

Reviewing the state of art and the state of research, the work undertaken by the University of Stuttgart and Technical University of Dresden (in continuation of the work undertaken by the "Institut für Bergbausicherheit Leipzig") is of high interest. Both universities have a strong presence with their main research about steel wire ropes.

The method Leipzig based on research of Jehmlich and Steinbach as well as the method Stuttgart based on research of Feyrer representing regression models to determine the attainable number of bending cycles of a wire rope subject to several influencing factors and 
parameters. Both methods, differing in test conditions and evaluation of the results, have already been considered as valuable input for the German guideline VDI 2358:2012-12 Wire ropes for mechanical handling equipment. [5]

\subsection{Method Leipzig}

The method Leipzig lays down a mathematical estimate in line with the Wöhler-line-system based on endurance tests with known statistical variances of the failure probability to calculate the attainable number of bending cycles of a wire rope in a rope drive system.

In the event of strain due to the rope tension force and bending and compression of rope drive elements, there are stress combinations acting in the wires of a wire rope that could lead to fatigue cracks. To calculate the stresses, certain parameters like the $\mathrm{D} / \mathrm{d}$-ratio of the rope drive system, the rope force or load spectrum, the nominal strength of the wires as well as the rope design itself must be considered. The method Leipzig summarizes these stresses to a strain $y$ formula and sets up a single-parameter Wöhler-line-system with strain $y$ over bending cycles $N$. Thus, the attainable number of bending cycles $N$ can be determined under consideration of the failure probability. To calculate the compressive stress, the contact conditions of the outer wires of the outer strands to the sheaves and wire rope core are considered which is a notably feature of the method Leipzig. That enables to assess the inner rope deterioration without yet visible wire break development. [6, 7]

$$
\begin{aligned}
& y=\frac{1}{R} \times\left(1,04 \times \frac{R}{v}+\frac{0,6 \times E}{K L^{2} \times \frac{D_{G}}{d}}+K L \times L \times B \times \sqrt{\frac{\pi}{4} \times \frac{f \times R}{v \times \frac{D_{G}}{d}}}\right) \\
& N^{P A \%}=\frac{H^{P A} \%}{y^{C L}}
\end{aligned}
$$

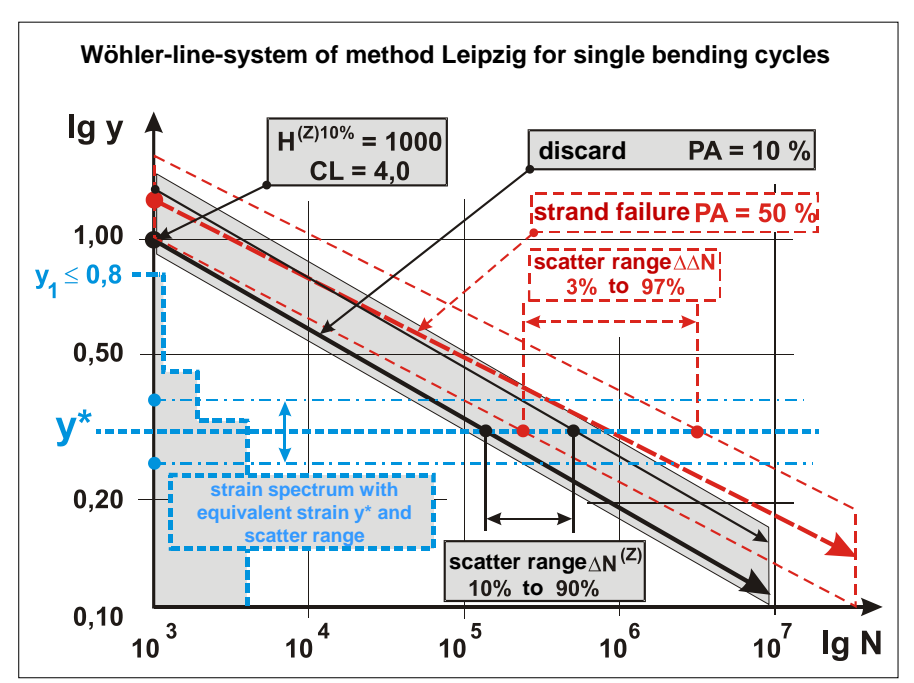

Figure 1:

Wöhler-line-system method Leipzig [7]

A full description and background details of the method Leipzig can be found in [6]. 


\subsection{Method Stuttgart}

The method Stuttgart goes back to Feyrer under whose leadership thousands of bending tests have been conducted and evaluated since the 1980s. The empirical findings have been transferred into lifetime diagrams of different wire ropes and utilized to develop a linear regression model to determine the number of bending cycles $N$ of a wire rope, expressed by the well-known Feyrer formula.

$$
\begin{aligned}
\lg N=b_{0} & +\left(b_{1}+b_{3} \times \lg \frac{D}{d}\right) \times\left(\lg \frac{S}{d^{2}}-0.4 \times \lg \frac{R_{0}}{1770}\right) \\
& +b_{2} \times \lg \frac{D}{d}+\lg f_{d}+\lg f_{L}+\lg f_{C}
\end{aligned}
$$

The method Stuttgart considers the most important influences on the number of bending cycles like the rope tensile force $S$ and the D/d-ratio of a rope drive systems. Furthermore, different endurance factors $f_{j}$ and regression coefficients $b_{i}$ have been derived from the empirical findings and incorporated to the Feyrer formula.

A lifetime diagram of a wire rope drawn in a logarithm scale is typically represented by straight lines for constant $\mathrm{D} / \mathrm{d}$-ratios. The lifetime diagram shows that at a certain high tensile force, the number of bending cycles declines suddenly. This limit of the tensile force where the number of bending cycles starts to decline is called the Donandt force and the kink in the lifetime diagram is called Donandt point respectively.

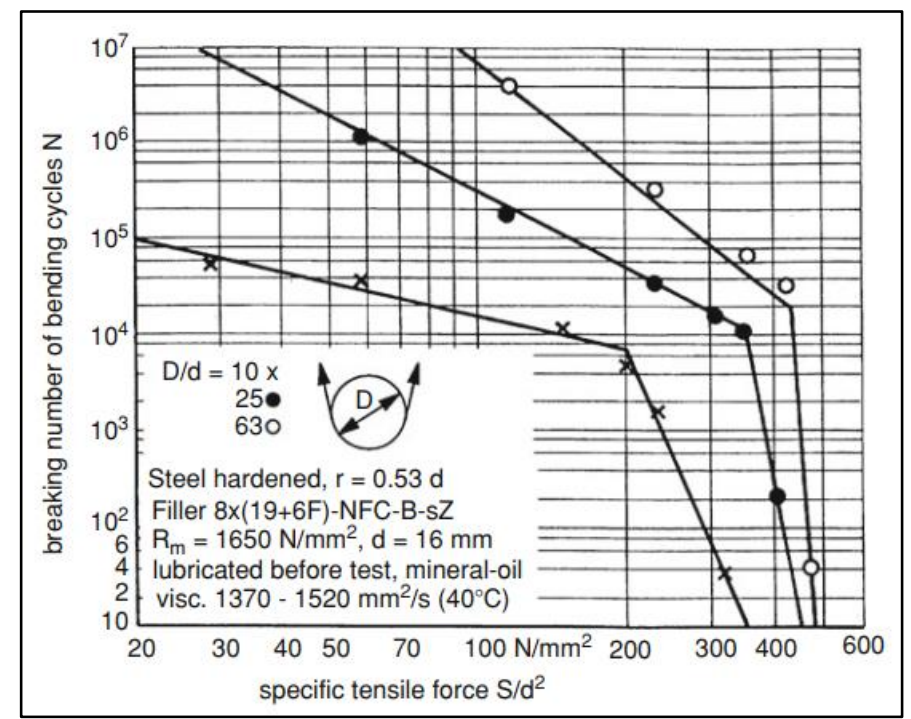

Figure 2:

Lifetime diagram of a Filler rope [8] p. 220

A full description and background details of the method Stuttgart can be found in [8].

\section{A First Linkage to Scientific Studies: The Concept of EN 13001-3-2}

The European standard EN 13001-3-2:2014 Cranes - General design - Part 3-2: Limit states and proof of competence of wire ropes in reeving systems has been prepared by the Technical Committee CEN/TC 147. [4] EN 13001-3-2 applies the limit state method and outlines proofs of competence for static strength and fatigue strength. The latter was 
developed considering the findings from Feyer and is based on the Feyrer formula (3). Comparing the original method Stuttgart as well as the method Leipzig with the concept of EN 13001-3-2, the European standard determines a higher total number of bending cycles of a wire rope until discard. [9] This finding was discussed at length and comparative calculations and studies disclosed the reasons of the deviation. [7, 9] The total number of bending cycles during the rated lifetime of a wire rope provides the basis for the wire rope dimensioning. The critical issue is that the total number of bending cycles during the design life of a rope $w_{\text {tot }}$ is predetermined by the total number of working cycles of a crane $C$ and the number of bending cycles per movement $w$ that relates to the number of ropes specified for the design life of a crane $l_{r}$ which in turn could be freely determined. [9]

In addition, the fatigue proof of competence of EN 13001-3-2 is based on assumptions that are either incorrect or cannot be comprehended by means of the method Stuttgart nor Leipzig. Formula 15 of EN 13001-3-2 (see formula (4)) shows a relationship of the increasing $\mathrm{D} / \mathrm{d}$-ratio and the increasing number of bending $w_{\text {tot }}$.

$$
\frac{D}{d} \sim 1,125^{\log _{2}\left(w_{t o t}\right)}
$$

It is also stated that the lifetime curve of a rope has a constant slope of $m=3$. [4, section 6.1] This assumption is refuted by calculations that disclosed that the slope changes with the D/d-ratio and thus cannot be constant. [7]

The relative total number of bendings $v_{r}$ relates the total number of bendings during the design life of a rope $w_{t o t}$ to the number of bendings at reference point $w_{D}$ with $w_{D}=5 \times 10^{5}$ of an unknown Wöhler-line with a constant slope of $m=3$. [4, section 6.3.4] Also this constant number of $w_{D}$ was assumed to be too high.

$$
v_{r}=\frac{w_{t o t}}{w_{D}}
$$

The way of calculating $w_{\text {tot }}$ representing the total number of bendings during the design life of a rope resulted to a number of bendings that a wire rope could actually not endure and thus is not in accordance with the number of bending cycles $N$ of the method Stuttgart nor the method Leipzig. A major critique of the concept of EN 13001-3-2:2014 is that the interpretation of $w_{\text {tot }}$ is misleading and this higher total number of bendings could lead to a misinterpretation of the design life of a rope and thus leading to a safety issue.

The concept of EN 13001-3-2:2014 considers the findings of Feyrer but incorporated wrong assumptions and derived wrong relationships of critical parameter. Those shortcomings can be eliminated by proper calculations and assumptions thereof based on the scientific results of the method Stuttgart and method Leipzig.

\section{The New Concept of ISO/WD 16625}

Starting point of the standardization work was to determine the necessary scope of revision of ISO 16625:2013 and subsequently to review any potential input available. The evaluation of the shortcomings of EN 13001-3-2 gave significant impetus to study the method Stuttgart and method Leipzig and the scientific results thereof. As an outcome, a new approach was 
considered to develop a new concept of ISO/WD 16625 that could eliminate the issues identified and will meet the objectives set.

The new concept of ISO/WD 16625 has its foundation on a new defined reference point that could be determined by assuming that a regression calculation by the method Stuttgart could be done for forces exceeding the Donandt force. From a mathematical standpoint such regression calculation is defined, although a wire rope in a rope drive system exposed to such high forces will fail after a comparable small number of bending cycles. The graphical representation of this mathematical approach (refer to formula (6) in conjunction with formula (3)) is simple: the straight lines of different D/d-ratio in a Wöhler diagram of one wire rope type will be extended until they intersect at a common point. This point is a virtual reference point, defined by a specific reference force $S_{r e f} / d^{2}$ and a reference number of bending cycles $w_{\text {ref }}$, derived from formula (6). [7]

$$
\begin{aligned}
& \lg \left(N_{1}\right)=\lg \left(N_{2}\right) \text { with }\left(\frac{D_{1}}{d}\right) ;\left(\frac{D_{2}}{d}\right) \\
& \frac{S_{r e f}}{d^{2}}=10 \frac{\left(b_{3} \times 0,4 \times \log \left(\frac{R_{0}}{1770}\right)-b_{2}\right)}{b_{3}} \\
& w_{\text {ref }}=10^{b_{0}+b_{1} \times\left(\frac{-b_{2}}{b_{3}}\right)+\left(\lg \left(f_{d}\right)+\lg \left(f_{L}\right)+\lg \left(f_{C}\right)\right)}
\end{aligned}
$$

Above mathematical approach proves that such a reference point would exist if a wire rope could withstand forces higher than the Donandt force. In conclusion, the virtual reference point could be utilized to determine the total number of bending cycles $N$ by a simplified calculation, less complex than the regression calculations of the method Stuttgart or method Leipzig, but comparable to the scientific results. [7]

$$
N=w_{t o t}=\left(\frac{S_{r e f}}{S}\right)^{m} \times w_{r e f}
$$

Utilizing formula (7) and (8), it could further be proven that formula (9) and formula (3) are equivalent and that $m$ can be derived as follows:

$$
m=-\left(\lg \frac{D}{d} \times b_{3}+b_{1}\right)
$$

The parameters of interest can be calculated by simply inserting values of the regression coefficients $b_{i}$ that have been empirically determined by bending tests conducted by Feyrer. [8] Those empirical findings of Feyrer can be utilized to further simplify the formula to calculate $m$ which in turn is more feasible from a standardization work point of view and in particular if the regression coefficients $b_{i}$ of a specific wire rope construction are not known. [7]

$$
m=1,125 \frac{D}{5 \times d}
$$

To relate the minimum rope breaking force $F_{\min }$ to the reference force $S_{r e f}$, a parameter $\gamma_{r e f}$ is introduced.

$$
\gamma_{\text {ref }}=\frac{F_{\text {min }}}{S_{\text {ref }}}
$$


Studies and calculations undertaken by the expert members of WG3 confirmed that applying formula (9) to calculate $w_{\text {tot }}$ and formula (11) for $m$ in function with the dynamic factor, risk coefficient, load spectrum factor and factors for further influences results in a total number of bending cycles lower than the total number of bending cycles until discard that have been determined in bending tests. [7]

Further details of the mathematical derivation can be found in [7].

\section{The Current Status of ISO/WD 16625}

The new concept introduced in the previous chapter established the framework of the working draft ISO/WD 16625 that outlines proofs of competence for running ropes in single layer as well as multi-layer spooling and proofs of competences for stationary ropes. Furthermore, the document structure and format of the proofs of competences from EN 13001-3-2:2014 were partly adopted.

For running ropes, the static proof of competence follows the same approach as given in EN 13001-3-2:2014, but some clarification on the interaction of the rope force increasing factors $f_{s i}$ have been implemented and the determination of the equivalent force $F_{\text {equ }}$ has been enhanced. To calculate the limit design force $F_{R d, s}$, a reduction factor due to the type of rope termination $f_{S 4}$ is additionally considered.

The fatigue proof of competence implements the concept as stated in the previous chapter: $F_{\text {ref }}$ and $w_{\text {ref }}$ are introduced and $m$ is in dependency of the D/d-ratio instead of a constant number. The calculation of the maximum number of bending cycles $w$ given by a reeving system has been clarified: the fact that the $\mathrm{D} / \mathrm{d}$-ratio increases $w$ is now incorporated in the calculation formula by the exponent $m$. Also, the calculation of the limit design rope force $F_{R d, f}$ has been enhanced: $m$ is in dependency of the D/d-ratio, a virtual reference force $F_{r e f}$ is introduced instead of the specified minimum breaking force, the value of the minimum rope resistance factor $\gamma_{r f}$ is reduced and a factor $\gamma_{r f D}$ is introduced to prevent from exceeding the Donandt force. This minimum rope resistance factor $\gamma_{r f D}$ is a combination of a correlation factor to describe the Donandt force depending on the minimum rope breaking force $F_{\text {min }}$ and the $\mathrm{D} / \mathrm{d}$-ratio and a safety factor. Furthermore, $w_{\text {tot }}$ is clarified and $w_{\text {ref }}$ is corrected as previously mentioned. The calculation of the relative total number of bending cycles $v_{r}$ is enhanced. Based on the scientific results from Feyrer [8], a rope diameter factor $f_{w 2}$ and a rope bending length factor $f_{w 3}$ are introduced that have to be considered in addition to other factors of further influence to $w_{r e f}$ when calculating $v_{r}$.

In EN 13001-3-2:2014 the requirements of multi-layer spooling are not sufficiently considered. The fatigue proof of competence for single layer is applied and only one additional factor introduced covers the impact of multi-layer spooling to reduce the limit design rope force. The ISO/WD 16625 states a separate fatigue proof of competence for multi-layer spooling following the structure of the proof of competence for fatigue strength of running ropes in single layer spooling, but differs in the relevant rope force increasing factors $f_{S i}$ to be applied as well as calculating the limit design rope force $F_{R d, m}$. 
For stationary ropes, the static proof of competence follows the same approach as given for running ropes. The fatigue proof of competence has been revised to incorporate the scientific findings of the method Stuttgart and the method Leipzig and to reflect empirical verified results from tension-tension tests conducted by the University of Stuttgart.

Compared to the current edition of ISO 16625:2013, annexes either normative or informative, have been introduced to provide guidance on

- the number of relevant bending cycles,

- the determination of the maximum tensile force in the ropes of multi-rope grabs,

- a correlation of the minimum design factor $Z_{p}$ and safety level,

- a new approach to calculate the assumed number of hoist ropes $l_{r}$ during the design life of a crane.

The standardization work from technical point of view is nearly completed and only some finetuning is needed prior to proceed to the next stage - the committee stage - in ISO standardization process.

\section{Conclusion}

The stated objectives of a revision of ISO 16625 have been met although the standardization work for stationary ropes at the time of this publication is not yet finalized. The state of research with the scientific results from the method Stuttgart and the method Leipzig have been of highly valuable input to provide a foundation for the new concept of ISO/WD 16625. The working group WG3 of ISO/TC 96 SC3 addressed the shortcomings of EN 13001-3-2:2014 to provide a fatigue proof of competence for running ropes to enhance the determination of the limit design rope force. A separate proof of competence of fatigue strength for running ropes in multi-layer spooling is introduced, too. The new concept implemented in ISO/WD 16625 ensures that modern methods like the proof of competence with a scientific based foundation supports the safe dimensioning and selection of a wire rope in a rope reeving system.

\section{Acknowledgement}

The authors would like to thank the expert members of the working group WG3 of ISO/TC 96 SC3 for their support and contribution to revise and enhance ISO/WD 16625. 


\section{List of Symbols}

\begin{tabular}{|c|c|}
\hline Symbol & Description \\
\hline$B$ & Wire contact factor \\
\hline$b_{i}$ & Constants, regression coefficients \\
\hline$C$ & Total number of working cycles during the design life of a crane \\
\hline$C L$ & Strain exponent \\
\hline$D$ & Sheave diameter \\
\hline$D_{G}$ & Bending diameter at bottom of groove \\
\hline$d$ & $\begin{array}{l}\text { Nominal diameter of the wire (method Leipzig) } \\
\text { Nominal rope diameter (method Stuttgart) }\end{array}$ \\
\hline$E$ & Modulus of elasticity of the rope wire \\
\hline$F_{\text {equ }}$ & Equivalent force \\
\hline$F_{\min }$ & Minimum rope breaking force \\
\hline$F_{R d, f}$ & Limit design rope force for the proof of fatigue strength \\
\hline$F_{R d, m}$ & Limit design rope force for multi-layer spooling \\
\hline$F_{R d, s}$ & Limit design rope force for the proof of static strength \\
\hline$F_{\text {ref }}$ & Virtual reference rope tension force \\
\hline$f$ & Fill factor \\
\hline$f_{d}$ & Endurance factor rope diameter \\
\hline$f_{C}$ & Endurance factor rope core \\
\hline$f_{L}$ & Endurance factor bending length \\
\hline$f_{S i}$ & Rope force increasing factors \\
\hline$f_{S 4}$ & Rope force reduction factor die to the type of rope termination \\
\hline$f_{w 2}$ & Factor of rope diameter influence \\
\hline$f_{w 3}$ & Factor of rope bending length influence \\
\hline$H$ & Constant operation period \\
\hline$K L$ & Construction factor wire rope \\
\hline$L$ & Wire factor \\
\hline$l_{r}$ & $\begin{array}{l}\text { Number of ropes used during the design life of the crane (EN 13001-3-2) } \\
\text { Number of ropes assumed during the design life of a crane (ISO/WD 16625) }\end{array}$ \\
\hline$m$ & Slope of the lifetime curve of a rope \\
\hline$N$ & (Attainable) Number of bending cycles \\
\hline$P A \%$ & Occurrence probability respectively failure probability \\
\hline$R$ & Nominal tensile strength of the rope wire \\
\hline$R_{0}$ & Nominal tensile strength \\
\hline$S$ & Rope tensile force \\
\hline$S_{\text {ref }}$ & (Virtual) Reference rope tension force \\
\hline \multirow[t]{2}{*}{$w$} & Number of relevant bendings per movement (EN 13001-3-2) \\
\hline & Maximum number of bending cycles given by a reeving system (ISO/WD 16625) \\
\hline$w_{D}$ & Number of bendings at reference point (EN 13001-3-2) \\
\hline$w_{\text {ref }}$ & Number of bending cycles at reference point (ISO/WD 16625) \\
\hline$w_{\text {tot }}$ & (Calculated) Total number of bending cycles during the design life of a rope \\
\hline$y$ & Strain \\
\hline$Z_{p}$ & Minimum design factor \\
\hline$\gamma_{r e f}$ & Factor to increase $F_{\min }$ to virtual rope tension force $F_{r e f}$ at reference point \\
\hline$\gamma_{r f}$ & Minimum rope resistance factor (fatigue) \\
\hline$\gamma_{r f D}$ & Minimum rope resistance factor to prevent exceeding the Donandt force \\
\hline$v$ & Safety factor \\
\hline$v_{r}$ & Relative total number of bending cycles \\
\hline
\end{tabular}




\section{References}

[1] Cranes and hoists - Selection of wire ropes, drums and sheaves, ISO 16625:3013

[2] Cranes and lifting appliances - Classification - Part 1: General, ISO 4301-1:1986

[3] Golder, M.: As Time Goes By, Hoist Magazine, August 2016

Golder, M., Wagner, G.: As time goes by: classification of hoists, cranes and lifting equipment [Online]. Available: http://www.hoistmagazine.com/content/GolderPaper.pdf

[4] Cranes - General Design - Part 3-2: Limit states and proof of competence of wire ropes in reeving systems, EN 13001-3-2:2014

[5] Wire ropes for mechanical handling equipment, VDI 2358:2012-12

[6] Steinbach, G., Anders, M., Ryk, D.: Betriebsdauer in Seiltrieben - Berechnung der Biegewechselzahl Methode Leipzig, Exklusivbeitrag, Hebezeuge Fördermittel, 5, pp. 34-35, 2018

[7] Golder, M., Anders, M., Novak, G., Eiwan, Ch.: New approach for ISO 16625 in Proceedings of the XXIII International Conference on Material Handling, Constructions and Logistics, MHCL 2019, Vienna, Austria

[8] Feyrer, K.: Wire Ropes, 2nd ed. Heidelberg, Springer Verlag, 2015

[9] Steinbach, G., Anders, M., Ryk, D.: Drahtseile in Seiltrieben nach DIN EN 13001-3-2:2014-12 Bemessungsbiegewechselzahl und Realbiegewechselzahl, Exklusivbeitrag, Hebezeuge Fördermittel, no. 1, pp. 1-23, 2016 